\title{
Antitumor effects of the hyaluronan inhibitor 4-methylumbelliferone on pancreatic cancer
}

\author{
ERI YOSHIDA ${ }^{1}$, DAISUKE KUDO ${ }^{1}$, HAYATO NAGASE ${ }^{1}$, HIROSHI SHIMODA ${ }^{2}$, SHINICHIRO SUTO $^{3,4}$, \\ MIKA NEGISHI $^{3,4}$, IKUKO KAKIZAKI ${ }^{4}$, MASAHIKO ENDO ${ }^{3}$ and KENICHI HAKAMADA ${ }^{1}$
}

\begin{abstract}
Departments of ${ }^{1}$ Gastroenterological Surgery and ${ }^{2}$ Anatomical Science, Hirosaki University, Graduate School of Medicine; Departments of ${ }^{3}$ Glycobiomedicine and ${ }^{4}$ Glycotechnology, Center for Advanced Medical Research, Hirosaki University, Graduate School of Medicine, Hirosaki, Aomori 036-8562, Japan
\end{abstract}

Received March 1, 2015; Accepted April 22, 2016

DOI: $10.3892 / 01.2016 .4930$

\begin{abstract}
Hyaluronan (HA) is a major component of the extracellular matrix (ECM), and influences tumor invasion and metastasis. In a previous study, the present authors reported for the first time that 4-methylumbelliferone (MU) inhibited HA synthesis and suppressed tumor growth. However, the localization of HA and the changes in ECM morphology caused by $\mathrm{MU}$ in pancreatic cancer remain to be examined in detail. In the present study, the cytotoxicity of MU and its effect on cellular proliferation was evaluated in the human pancreatic cancer cell line MIA PaCa-2. The amount of HA synthesized and the retention of HA around the cells were quantitatively and immunohistochemically analyzed in vitro and in vivo. Structural changes in the ECM in the tumor tissue were investigated using an electron microscope. MU treatment led to a decrease in extracellular HA retention, as evidenced by a particle exclusion assay and immunohistochemical staining. Cell proliferation was suppressed by MU in a dose-dependent manner. The release of lactate dehydrogenase into the culture medium due to damage to the cellular membrane did not increase following MU administration. In tumor-inoculated mice, MU suppressed any increase in tumor volume and decreased the quantity of HA. Electron microscopy revealed that MU attenuated the intercellular space and caused it to be less cohesive. These data indicate that MU inhibits HA synthesis and reduces the amount of HA in the ECM while exhibiting no obvious cytotoxic effect. These findings suggest
\end{abstract}

Correspondence to: Professor Kenichi Hakamada, Department of Gastroenterological Surgery, Hirosaki University, Graduate School of Medicine, 5 Zaifu-cho, Hirosaki, Aomori 036-8562, Japan E-mail: hakamada@hirosaki-u.ac.jp

Abbreviations: HA, hyaluronan; HAS, hyaluronan synthase; MU, 4-methylumbelliferone; DMEM, Dulbecco's modified Eagle's medium; DMSO, dimethyl sulfoxide; PBS, phosphate-buffered saline; ECM, extracellular matrix

Key words: pancreatic cancer, 4-methylumbelliferone, hyaluronan, extracellular matrix, chemosensitizer that MU has potential as a novel therapeutic agent for pancreatic cancer.

\section{Introduction}

Hyaluronan (HA) is a high molecular weight glycosaminoglycan composed of repeating disaccharide units of D- $N$-acetylglucosamine (GlcNAc) and D-glucuronic acid (GlcUA) in the structure GlcNAc- $\beta-(1 \rightarrow 4)$ GlcUA- $\beta-(1 \rightarrow 3)(1)$. Due to its physicochemical composition, HA is able to trap large amounts of water, and its solutions are viscous and elastic (1). HA is synthesized from the precursors uridine 5'-diphosphoglucoronic acid (UDP-GlcUA) and uridine diphosphate $N$-acetylglucosamine (UDP-GlcNAc) (2). The synthesis occurs at the inner leaflet of the plasma membrane by a membrane-associated enzyme termed hyaluronan synthase (HAS) (2). In numerous tissues, $\mathrm{HA}$ is a major component of the extracellular matrix (ECM) and is non-covalently bound to other components (2). In normal tissues, the presence of HA creates an environment that facilitates cellular proliferation and migration (3). Additionally, $\mathrm{HA}$ is required for certain physiological processes such as embryonic development and wound healing (3). In cancer, however, the properties of HA enhance tumor invasion, growth, angiogenesis and metastasis (3-5). Previous studies have revealed that HA participates in the cell adhesion (6) and migration (7) phases of tumor metastasis. In several human tumors of epithelial origin, including breast (4), ovarian (8), prostate (9), gastric (10) and colon cancer (11), accumulation of HA in the tumor tissue was associated with invasive and metastatic properties, and led to a worse prognosis.

Previous studies have used 4-methylumbelliferone (MU) as a fluorescent indicator to measure various types of enzymatic activity (12). The present authors have reported that MU inhibits HA synthesis and ECM formation in cultured human skin fibroblasts (13). Using rat $3 \mathrm{Y} 1$ fibroblasts that stably expressed HAS2, a novel mechanism of MU-mediated inhibition of HA synthesis was demonstrated, in which glucuronidation of MU by endogenous uridine diphosphate (UDP)-glucuronyl transferase results in depletion of UDP-GlcUA (14). Subsequently, the present authors reported that HA synthesis in B16F-10 melanoma cells is suppressed by MU, and that knockdown of extracellular HA decreases cellular adherence and locomotion in vitro (15). In 
addition, the present authors have demonstrated that suppression of HA in the liver of C57BL/6 mice reduces inhabitation of metastatic nodules in vivo when melanoma cells were injected into the lateral tail vein of the mice (16). MU has been widely investigated as an inhibitor of HA synthesis, and has been proposed as an anticancer agent. Piccioni et al (17) reported that MU induced apoptosis in mouse hepatocellular carcinoma models, and led to a decrease in the amount of hepatic stellate cells. Lokeshwar et al (18) reported that MU inhibited the proliferation and invasion of prostate cancer cells, while Pályi-Krekk et al (19) demonstrated that MU reduced the amount of HA in breast cancer cells, which led to enhanced binding of trastuzumab.

Pancreatic cancer is one of the most malignant neoplasms, and $80-85 \%$ of patients present with advanced unresectable tumors (20). The annual number of mortalities caused by pancreatic cancer has been gradually increasing, while the prevalence and mortality of other common types of cancer have been declining (21). Despite continuous improvements in the detection and management of pancreatic cancer, only $4 \%$ of patients live for 5 years subsequent to diagnosis (20-22). One of the major reasons for this dismal prognosis is the poor response of pancreatic cancer cells to the majority of chemotherapeutic agents currently available (20). Therefore, a novel therapeutic agent for the treatment of progressive pancreatic cancer is urgently required.

Regarding the role of HA in human pancreatic tissue, a previous immunohistochemical study using human pancreatic cancer tissues revealed a stronger expression of HA and HAS2 in these tissues compared with healthy pancreas tissues, and that increased expression of HA and HAS2 was associated with a significantly poorer prognosis (23). Accordingly, the present authors considered the possibility that MU exerts an anticancer effect on pancreatic cancer. This hypothesis is supported by the results of Nakazawa et al (24), who reported that MU inhibited HA synthesis and ECM formation in primary and metastatic tumors of human pancreatic cancer cells. However, the distribution of HA in pancreatic cancer tissue remains unknown, and the structural changes caused by $\mathrm{MU}$ in the ECM have not been sufficiently investigated to date.

In the present study, the in vitro antiproliferative effect and cytotoxicity of MU were examined in MIA PaCa-2, a human pancreatic cancer cell line. HA synthesis and localization in cancer tissues were analyzed quantitatively and immunohistochemically. Furthermore, MU-mediated structural changes of cancer cells and ECM in the tumor tissue were investigated using an electron microscope. The suitability of MU as an anticancer agent for pancreatic cancer is also discussed.

\section{Materials and methods}

Materials. The 4-methylumbelliferone (MU) and hyaluronidase from Streptomyces hyalurolyticus were purchased from Wako Pure Chemicals Industries, Ltd. (Osaka, Japan). Actinase E was purchased from Kaken Pharmaceutical Co., Ltd. (Tokyo, Japan). Dulbecco's modified Eagle's medium (DMEM) was purchased from Nacalai Tesque, Inc. (Kyoto, Japan). All other reagents were of analytical grade and were obtained from commercial sources.
Tumor cells. The human pancreatic cancer cell line MIA PaCa-2 was kindly provided by the Department of Pharmacy of Hirosaki University Hospital (Hirosaki, Japan). The cells were routinely maintained as monolayer cultures in DMEM supplemented with $10 \%$ heat-inactivated fetal bovine serum (Nichirei Biosciences, Inc., Tokyo, Japan), L-glutamine (Nacalai Tesque, Inc.), sodium pyruvate (Nacalai Tesque, Inc.) and antibiotic antimycotic solution (Sigma-Aldrich Japan Co., LLC., Tokyo, Japan) at $37^{\circ} \mathrm{C}$ in a mixture of $5 \% \mathrm{CO}_{2}$ and $95 \%$ humidified air.

Mice. A total of 30 male C.B-17/lcr-scid mice were purchased from Japan Clea (Tokyo, Japan). The mice were housed under controlled light-dark cycles, temperature and humidity, with water and food ad libitum. The mice were used when they were 6-week-old and weighted $\sim 25 \mathrm{~g}$. All animal experiments were performed according to the Guidelines for Animal Experimentation of Hirosaki University (Hirosaki, Japan).

Particle exclusion assay. Cell surface HA was visualized using a particle exclusion assay. Fixed horse erythrocytes (Nippon Biotest Laboratories Inc., Tokyo, Japan) were reconstituted in $9.6 \mathrm{mM}$ phosphate-buffered saline (PBS; pH 7.4; Nacalai Tesque, Inc.) at a density of $5 \times 10^{8}$ cells $/ \mathrm{ml}$. MIA PaCa-2 cells were cultured in 100-mm dishes. Extracellular HA was visualized under a light microscope (IX71N-22/PH; Olympus Corporation, Tokyo, Japan) by adding the erythrocyte suspension $(3 \mathrm{ml})$ to the growth medium, with or without MU. To determine the composition of the extracellular halo, MU-free dishes were pre-incubated with $3.0 \mathrm{U} / \mathrm{ml}$ Streptomyces hyalurolyticus hyaluronidase (Wako Pure Chemicals Industries, Ltd.) for $1 \mathrm{~h}$ prior to the assay (25).

Immunohistochemical staining of pancreatic cancer cells. Chamber slides were used for staining cells (Thermo Fisher Scientific, Inc., Waltham, MA, USA). Medium ( $1 \mathrm{ml}$ ) containing $1 \times 10^{4} \mathrm{MIA} \mathrm{PaCa}-2$ cells was added to the chamber slides. Following 24-h incubation, 0.1-1.0 mM MU dissolved in dimethyl sulfoxide (DMSO; Wako Pure Chemicals Industries, Ltd.) was added, ensuring that the concentration of DMSO in the medium did not exceed $0.1 \%$. Upon 48-h incubation, cells were washed twice with PBS ( $2 \mathrm{ml} /$ wash), fixed with $4 \%$ paraformaldehyde buffered with PBS at room temperature for $2 \mathrm{~h}$ and rinsed twice with PBS. Following antigen retrieval, tissue samples were incubated for $32 \mathrm{~min}$ at $37^{\circ} \mathrm{C}$ with $2.5 \mu \mathrm{g} / \mathrm{ml}$ biotinylated HA binding protein (HABP; catalog no., BC41; Hokudo Co., Ltd., Osaka, Japan). Streptavidin horseradish peroxidase conjugate and 3,3-diaminobenzidine (DAB) from the iVIEW DAB universal kit (Ventana Medical Systems, Inc., Tucson, AZ, USA) was used to visualize the results. Negative controls were stained with HABP following digestion of the tissue sections with $3.0 \mathrm{U} / \mathrm{ml}$ Streptomyces hyalurolyticus hyaluronidase (26).

Analysis of HA synthesis in cells. Medium (9 ml) containing $6 \times 10^{5}$ MIA PaCa- 2 cells was seeded in a $100-\mathrm{mm}$ culture dish and incubated for $24 \mathrm{~h}$. Cells were incubated with 0.1-1.0 mM MU dissolved in DMSO. Following 48-h incubation, the medium was removed. Cells were washed twice with PBS $(5 \mathrm{ml} /$ wash) and suspended in PBS $(0.5 \mathrm{ml})$. The suspension was mixed with $5 \mathrm{ml}$ lysis buffer [1\% NP-40, $150 \mathrm{mM} \mathrm{NaCl}$, 
$50 \mathrm{mM}$ Tris- $\mathrm{HCl}$ buffer ( $\mathrm{pH} 8.0$ ), $0.5 \%$ sodium deoxycholate and $0.1 \%$ sodium dodecyl sulfate; Wako Pure Chemicals Industries, Ltd.], vortexed for $1 \mathrm{~min}$ and placed on ice for 30 min. Upon centrifugation (MRX-152; Tomy Seiko Co., Ltd., Tokyo, Japan) of the suspension at $10,000 \times \mathrm{g}$ at $4{ }^{\circ} \mathrm{C}$ for $10 \mathrm{~min}$, the supernatant containing $\mathrm{HA}$ was transferred into another tube and kept at $-80^{\circ} \mathrm{C}$ until analysis. HA was measured using an enzyme-linked binding protein assay kit in a sandwich format, according to the manufacturer's protocol (Biotech Trading Partners, Encinitas, CA, USA) (27).

Proteins were quantified using the dye-binding Bradford method (Bio-Rad Laboratories, Inc., Hercules, CA, USA), according to the manufacturer's protocol (28). Bovine serum albumin (Sigma-Aldrich Japan Co., LLC.) in $5 \mathrm{mM}$ Tris-HCl buffer ( $\mathrm{pH}$ 7.0; Wako Pure Chemicals Industries, Ltd.) was used as a standard.

Cell growth assay. Medium ( $2 \mathrm{ml})$ containing $1 \times 10^{5}$ cells was seeded into 6-well plates (Iwaki ${ }^{\circledR}$; Analytical Technologies Group, LLC, Groton, CT, USA). Following 12-h incubation, 0.1-1.0 mM MU dissolved in DMSO was added. Upon 24, 48 or 72-h incubation with MU, each well was washed twice with PBS $(5 \mathrm{ml} /$ wash), detached from the plates by addition of $0.5 \mathrm{ml}$ trypsin/ethylenediaminetetraacetic acid (EDTA; Thermo Fisher Scientific, Inc.) and suspended in $2 \mathrm{ml} \mathrm{PBS}$. The cell count of the suspensions was assessed using an automated cell counter (TC20 ${ }^{\mathrm{TM}}$; Bio-Rad Laboratories, Inc.) (29).

Lactate dehydrogenase $(\mathrm{LDH})$ assay. The cytotoxicity of MU was analyzed using LDH-Cytotoxic Test (Wako Pure Chemicals Industries, Ltd.) (30). Medium (50 $\mu 1)$ containing $5 \times 10^{4}$ cells was added to 96 -well plates (Iwaki ${ }^{\circledR}$; Analytical Technologies Group, LLC). Following 12-h incubation, 0.1-1.0 mM MU dissolved in DMSO was added, and cells were further incubated for $2 \mathrm{~h}$. Next, the plates were centrifuged (MRX-152; Tomy Seiko Co., Ltd.) at $158 \mathrm{x} \mathrm{g}$ for $3 \mathrm{~min}$, and the supernatants were collected. The concentration of LDH in the supernatants was measured at an absorbance (Abs) wavelength of $560 \mathrm{~nm}$ using a microplate spectrophotometer (xMark ${ }^{\mathrm{TM}}$; Bio-Rad Laboratories, Inc.). Cytotoxicity was calculated using the following formula, where $\mathrm{Abs}_{\text {sample }}$, $\mathrm{Abs}_{\text {neg }}$ and $\mathrm{Abs}_{\text {pos }}$ are the Abs values of the sample, negative control and positive control, respectively:

$$
\text { Cytotoxicity }(\%)=\left(\mathrm{Abs}_{\text {sample }}-\mathrm{Abs}_{\text {neg }}\right) /\left(\mathrm{Abs}_{\mathrm{pos}}-\mathrm{Abs}_{\text {neg }}\right) \times 100
$$

Analysis of tumor growth. A suspension of $4 \times 10^{6}$ MIA $\mathrm{PaCa}-2$ cells was subcutaneously injected into the dorsal tissue of the mice, and 2 weeks later, MU was orally administered at a dose of $2 \mathrm{~g} / \mathrm{kg} /$ day, mixed with bait in order to reduce stress in the animals. Once a week, tumor size was compared between the MU-treated $(n=14)$ and control groups $(n=15)$ using a caliper, and the tumor volume was calculated as length $\mathrm{x}$ width ${ }^{2} \mathrm{x} 0.52(31)$.

Analysis of HA synthesis in pancreatic cancer tissue. Mice were euthanized, and the tumors were removed. The dry weight of each tumor sample was measured upon desiccation at $60^{\circ} \mathrm{C}$ for $4 \mathrm{~h}$. Each sample was minced and digested overnight at $55^{\circ} \mathrm{C}$ with $0.25 \%$ actinase $\mathrm{E} / 10 \mathrm{mM}$ Tris- $\mathrm{HCl}$ $(1 \mathrm{ml} ; \mathrm{pH} 8.0)$, followed by incubation at $100^{\circ} \mathrm{C}$ for $10 \mathrm{~min}$ to terminate the reaction. Upon centrifugation of the suspension at $10,000 \mathrm{x} \mathrm{g}$ at $4^{\circ} \mathrm{C}$ for $10 \mathrm{~min}$, the supernatant containing HA was collected, and the concentration of HA was measured using an enzyme-linked binding protein assay kit in a sandwich format, as previously described $(27,32)$.

Immunohistochemical staining of tumor. The removed tumor was fixed in $10 \%$ formalin (Wako Pure Chemicals Industries, Ltd.) dissolved in $70 \%$ ethanol (Wako Pure Chemicals Industries, Ltd.) and 5\% glacial acetic acid (Wako Pure Chemicals Industries, Ltd.). The samples were embedded in paraffin (Wako Pure Chemicals Industries, Ltd.) using routine procedures (33), sliced at a thickness of $4 \mu \mathrm{m}$ (CRM-440; Sakura Finetek Japan Co., Ltd.) and analyzed using the iVIEW DAB Universal kit. Antigen retrieval was conducted using cell conditioning solution [CC1-Tris based EDTA buffer ( $\mathrm{pH} 8.0$ ); Ventana Medical Systems, Inc.], and tissue samples were then incubated for $32 \mathrm{~min}$ at $37^{\circ} \mathrm{C}$ with $2 \mu \mathrm{g} / \mathrm{ml}$ biotinylated HABP. The aforementioned iVIEW DAB Universal kit was used to visualize the results. Negative controls were stained with HABP following digestion of the tissue sections with $100 \mathrm{U} / \mathrm{ml}$ Streptomyces hyalurolyticus hyaluronidase (34).

Transmission electron microscopy. Several small pieces of tissue established by the transplantation of MIA PaCa-2 cells were immersed in Karnovsky's fixative (25\% glutaralldehyde, $2 \%$ paraformaldehyde and $0.1 \mathrm{M}$ cacodylate buffer) for $>24 \mathrm{~h}$ at $4^{\circ} \mathrm{C}$. Upon rinsing in $0.1 \mathrm{M}$ cacodylate buffer ( $\mathrm{pH} 7.2$; Wako Pure Chemicals Industries, Ltd.), the tissues were post-fixed in $0.1 \%$ ruthenium red (Wako Pure Chemicals Industries, Ltd.) and $2 \%$ osmium tetroxide solution (TAAB Laboratories Equipment, Bershire, England) overnight at $4^{\circ} \mathrm{C}$. Next, the tissues were dehydrated in a graded ethanol series and embedded in Epon 812 (Okenshoji Co., Ltd., Tokyo, Japan). Ultrathin sections were prepared, stained with uranyl acetate (TAAB Laboratories Equipment) and lead citrate (TAAB Laboratories Equipment), and examined under a JEM-1230EX transmission electron microscope (JEOL, Ltd., Tokyo, Japan).

Statistical analysis. Statistical analysis was performed using the Student's $t$-test. $\mathrm{P}<0.05$ was considered to indicate a statistically significant difference.

\section{Results}

Inhibition of HA synthesis in MIA PaCa-2 cells by MU. The effect of MU on HA synthesis in the surrounding ECM of MIA PaCa-2 cells was examined using a particle exclusion assay. When the cells were incubated without MU, the ECM halo could be observed (Fig. 1A), whereas no halo could be observed when the cells were incubated with 0.1 or $0.5 \mathrm{mM}$ MU (Fig. 1B and C, respectively). Cells treated with Streptomyces hyalurolyticus hyaluronidase prior to the assay also exhibited no halo (Fig. 1D). Immunohistochemical staining for $\mathrm{HA}$ indicated that MIA $\mathrm{PaCa}-2$ cells retained $\mathrm{HA}$ on their cell surface (Fig. 1E). However, HA staining by HABP could not be observed when the cells were incubated with $0.5 \mathrm{mM}$ MU (Fig. 1F), and cells treated with Streptomyces hyalurolyticus 

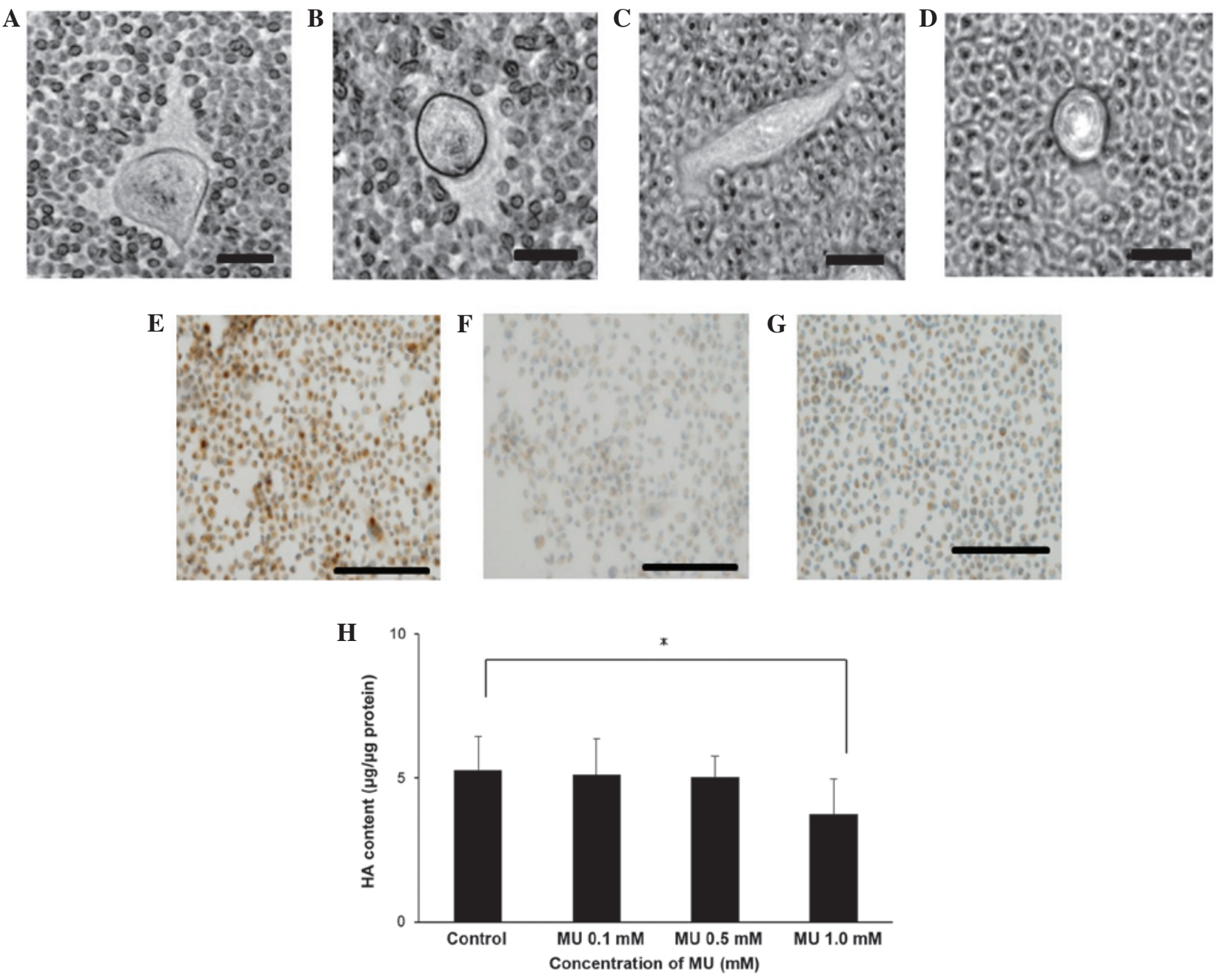

Figure 1. (A-D) Visualization of the ECM. The ECM surrounding MIA PaCa-2 cells was visualized using a particle exclusion assay in (A) control cells, (B) cells incubated with $0.1 \mathrm{mM}$ MU, (C) cells incubated with $0.5 \mathrm{mM} \mathrm{MU}$ and (D) cells incubated with $3.0 \mathrm{U} / \mathrm{ml}$ Streptomyces hyalurolyticus hyaluronidase. Bar size, $20 \mu \mathrm{m}$; magnification, $\mathrm{x} 400$; staining, biotinylated HA binding protein. Immunohistochemical staining of (E) control pancreatic cancer cells, (F) cells incubated with $0.5 \mathrm{mM}$ MU and (G) cells incubated with $3.0 \mathrm{U} / \mathrm{ml}$ Streptomyces hyalurolyticus hyaluronidase. Bar size, $100 \mu \mathrm{m}$; magnification, x200; staining, biotinylated HA binding protein. (H) Effect of MU on the synthesis of HA by MIA PaCa-2 cells. Cells were incubated with $0.1,0.5$ or $1.0 \mathrm{mM}$ MU for $48 \mathrm{~h}$, prior to the extraction and quantification of HA. Data are represented as the mean \pm standard error of the mean of eight replicates. ${ }^{~} \mathrm{P}<0.05$. ECM, extracellular matrix; MU, 4-methylumbelliferone; HA, hyaluronan.
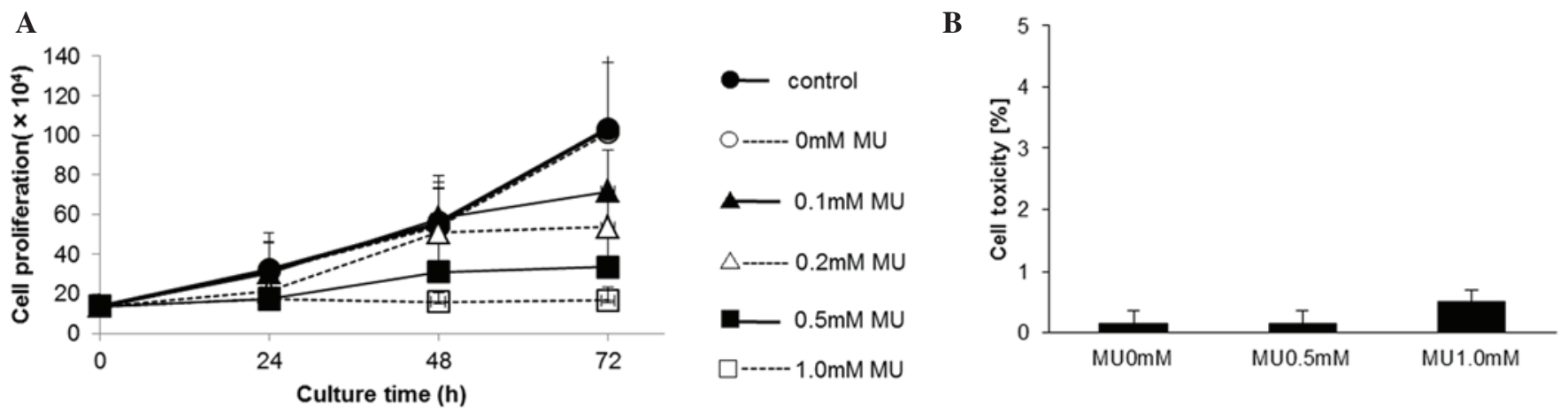

Figure 2. (A) Effect of MU on cell growth. MIA PaCa-2 cells were incubated with 0.0-1.0 mM MU and counted. Control contained medium only; 0 mM MU consisted of $0.1 \%$ dimethyl sulfoxide in medium (B) Cytotoxic effect of MU on MIA PaCa-2 cells. Data represent the mean of four independent assays. MU, 4-methylumbelliferone.

hyaluronidase prior to HABP treatment were not stained (Fig. 1G). Quantitative analysis of cellular HA was also performed (Fig. 1H). MU caused a decline in HA retention in a dose-dependent manner, and incubation with $1.0 \mathrm{mM}$ MU caused a $29 \%$ decrease of HA, compared with the control $(\mathrm{P}<0.05)$. 


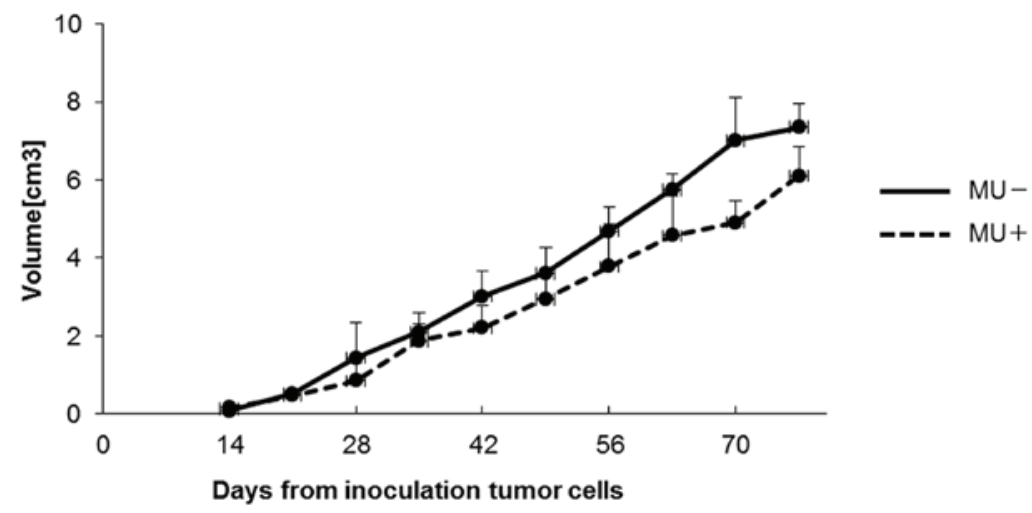

Figure 3. Size of the inoculated tumors. Tumors were measured with calipers and their volume was calculated. Data represent the mean of 14 mice. MU, 4-methylumbelliferone.

A

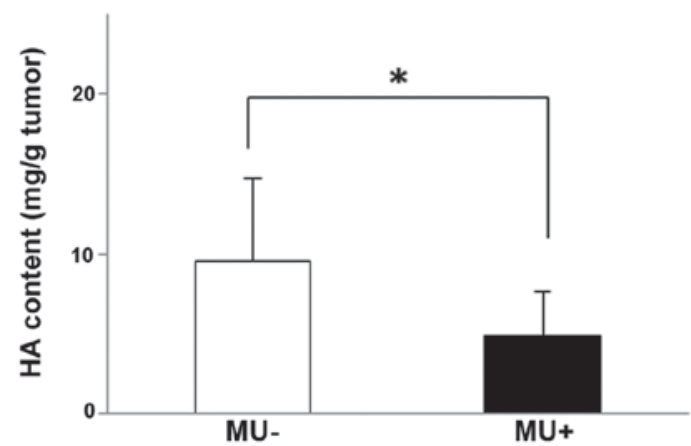

B

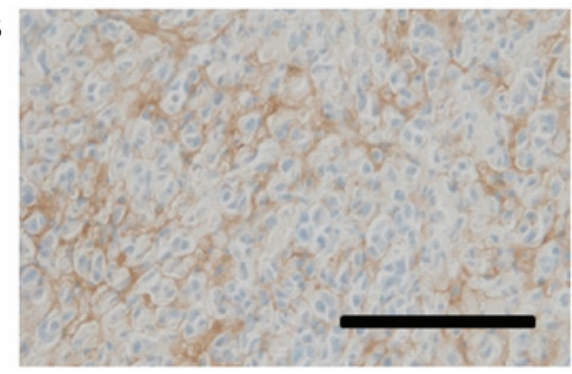

D

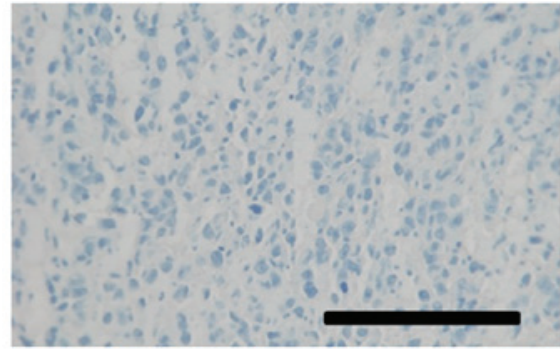

$\mathbf{C}$

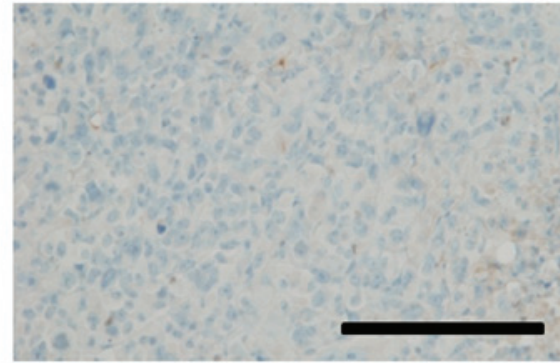

$\mathbf{E}$

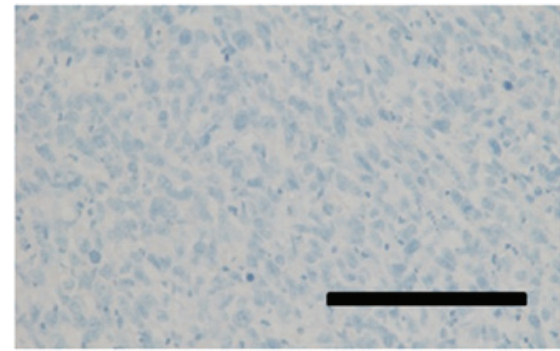

Figure 4. (A) Analysis of HA synthesis in pancreatic cancer tissue. The content of HA per $1 \mathrm{~g}$ of tumor tissue is shown. Data represent the mean \pm standard error of the mean of 9 mice. ${ }^{*} \mathrm{P}<0.05$. (B-E) Immunohistochemical staining of pancreatic tumors. (B) Untreated, (C) MU-treated, (D) untreated and incubated with Streptomyces hyalurolyticus hyaluronidase prior to staining with HABP and (E) MU-treated and incubated with Streptomyces hyalurolyticus hyaluronidase prior to staining with HABP pancreatic tumors were subjected to immunohistochemical analysis. Bar size, $100 \mu$ m; magnification, $\mathrm{x} 40$; staining, $\mathrm{HABP}$. MU, 4-methylumbelliferone; HA, hyaluronan; HABP, hyaluronan binding protein.

Effect of MU on the proliferation of MIA PaCa-2 cells. The proliferation of MIA PaCa-2 cells was evaluated using a cell counter, which revealed that MU inhibited cell proliferation in a dose-dependent manner. Upon 72-h incubation, cell proliferation was inhibited by $30.6 \%$ by $0.1 \mathrm{mM} \mathrm{MU}, 48.0 \%$ by $0.2 \mathrm{mM}$ MU and $67.5 \%$ by $0.5 \mathrm{mM}$ MU, compared with the control
(Fig. 2A). The cytotoxicity of MU was determined using an LDH assay. Following MU administration, the LDH activity did not increase in the culture medium (Fig. 2B).

Effect of MU on human pancreatic cancer in vivo. To examine the effect of MU in vivo, suspensions containing $4 \times 10^{6}$ MIA 

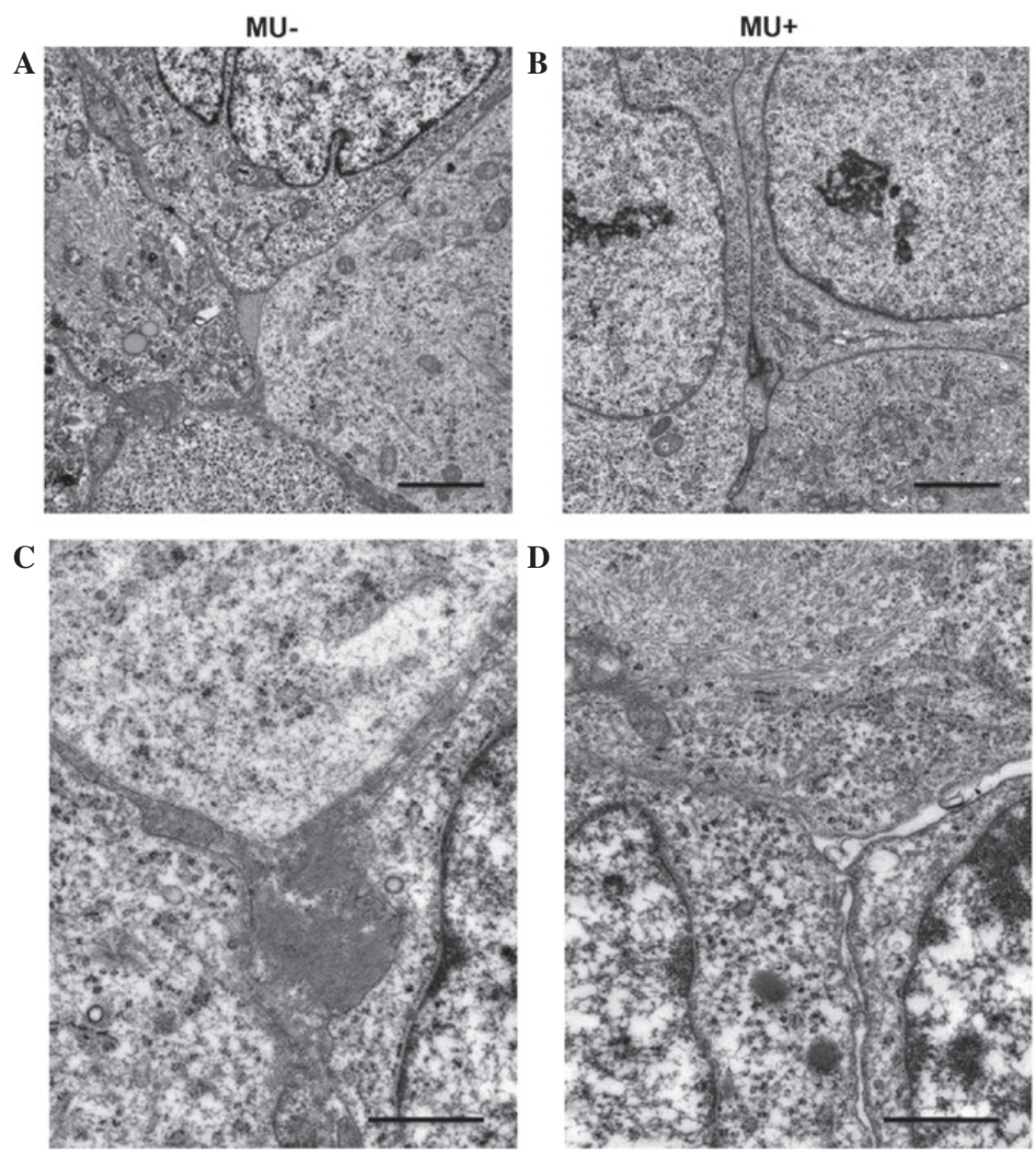

Figure 5. Electron micrographs revealed the stroma of (A and C) untreated and (B and D) 4-methylumbelliferone-treated pancreatic tumors. (A and B) Bar size, $2.5 \mu \mathrm{m}$; magnification, x25,000. (C and D) Bar size, $1.0 \mu \mathrm{m}$; magnification, x10,000. MU, 4-methylumbelliferone.

$\mathrm{PaCa}-2$ cells were subcutaneously injected into mice, and MU was administered orally every day. On day 70 post-inoculation, the tumor volume was $4.91 \mathrm{~cm}^{3}$ in the MU-treated group vs. $7.02 \mathrm{~cm}^{3}$ in the control group (Fig. 3). The majority of mice succumbed to cachexia, and no differences in body weight were observed between the treatment and control groups. HA content in tumors was $4.89 \mathrm{mg} / \mathrm{g}$ in the MU-treated group vs. $9.59 \mathrm{mg} / \mathrm{g}$ in the control group, indicating that the quantity of $\mathrm{HA}$ in the tumor was significantly $(\mathrm{P}<0.05)$ decreased by MU treatment (Fig. 4A). Immunohistochemical staining of the tumors demonstrated that HA was present around the cancer cells, and in comparison with the untreated controls, the levels of HA were reduced in mice that had been treated with MU (Fig. 4B and C). Tissue sections that had been treated with $100 \mathrm{U} / \mathrm{ml}$ Streptomyces hyalurolyticus hyaluronidase prior to staining with HABP exhibited no HA (Fig. 4D and E).

Effect of MU on the microenvironment of the ECM of cancer cells. Electron microscopy was used to detect changes in the microenvironment surrounding the inoculated MIA PaCa-2 cells. Cell nuclei exhibited numerous mitotic features. MIA $\mathrm{PaCa}-2$ cells had increased tumor cellularity, displayed a strong, proliferative capability and grew without stroma. In the MU-treated group, necrosis was suppressed, and the number of apoptotic bodies was not increased, compared with the control group. No disruption of the nuclei or differences in the morphology of the nuclei and cytoplasmic organelles were observed between the MU-treated and the control groups (Fig. 5A and B). By contrast, the intercellular space was less cohesive in the MU-treated group, compared with the control group. In addition, the MU-treated group exhibited interstitial oligochromia (Fig. 5C and D).

\section{Discussion}

HA is intimately involved in the biology of cancer (7). HA accumulates into the stroma of various human tumors and modulates the intracellular signaling pathways involved in cell proliferation and migration (6,7). Metastatic tumors are enriched in HA, and the healthy fibroblasts that surround malignant cells are stimulated to synthesize HA (35). HA-rich environments enhance tumor invasion and metastasis, and are associated with poorly differentiated phenotypes and poor prognosis in human adenocarcinoma (36). Delivery of macromolecules to cancer cells is inhibited by the ECM, since HA supplies a high intratumoral fluidic pressure, which prevents the diffusion and penetration of anticancer agents into the tumor tissue (37). This suggests that cancer cells are dependent on HA-rich environments for survival, self-replication, migration to other tissues and drug resistance. Therefore, regulation of HA metabolism is important 
for the treatment of cancer. Several studies have reported that MU inhibits the synthesis of HA and the preservation of HA in the ECM (13-15). As a result, MU has been widely investigated as an inhibitor of HA synthesis, and has been proposed as an anticancer agent (15-19). The anticancer effect of MU has been reported in various types of cancer, including malignant melanoma $(15,16)$, hepatocellular carcinoma $(17)$, prostate cancer (18) and breast cancer (19). However, the effect of MU on pancreatic cancer remains unknown. Pancreatic cancer has the worst prognosis of all solid tumors (20). Conventional treatments such as chemotherapy, molecular-targeted therapy, radiotherapy and combinations of all three hardly improve prognosis $(20,21)$. Accordingly, the present authors hypothesized that MU may be useful for the treatment of pancreatic cancer.

In the present study, MIA PaCa-2 cells were observed to retain $\mathrm{HA}$ on the cellular surface when they were not treated with MU; however, when MU was administered into the culture medium, this was suppressed, as evidenced by biochemical and immunohistochemical assays. Furthermore, MU inhibited cell proliferation in a dose-dependent manner without causing any damage to cell membranes. These results suggest that MU is able to inhibit the growth of pancreatic tumors by suppressing HA synthesis. Correspondingly, the volume of tumors formed in mice upon inoculation of MIA $\mathrm{PaCa}-2$ cells was reduced following oral administration of $\mathrm{MU}$, and a reduction on the levels of HA present in tumor tissue was confirmed by quantitative analysis. Immunohistochemical staining revealed that HA was abundant in the ECM surrounding the pancreatic cancer cells of the inoculated mice when the animals were not exposed to MU. By contrast, when treated with MU, a decrease in HA retention in the ECM was observed. Electron microscopy was used to examine the structural changes in the ECM, and the gap between the cells was observed to be weaker in the MU-treated group than in the untreated group. Structural changes in the ECM caused by MU may aid anticancer agents and immunocompetent lymphocytes to diffuse through the intercellular space and successfully reach the cancer cells. The remodeling of the ECM is therefore expected to act as an adjuvant chemosensitizer, thus enabling the treatment of otherwise intractable tumors. As a result, MU is a potentially useful anticancer therapeutic agent for pancreatic cancer.

An alternative method for controlling the cellular levels of HA is through genetic manipulation. However, HA deficiency leads to developmental problems. Camenisch et al (38) generated HAS2 knockout mice, and reported that targeted depletion of the HAS2 gene resulted in embryonic mortality due to extensive abnormalities in the development of the cardiovascular system. It has also been reported that HA is involved in various physiological processes that are essential for maintenance of life (3), and therefore, precise control over the extent of HA reduction is required for the successful clinical application of HA modulation as an anticancer treatment.

In the present study, MU treatment mediated an decrease in tumor volume, reduced the quantity of intratumoral HA and did not show any harmful effect on the animals. This is supported by the fact that MU has been used as a choleretic and antispasmodic agent for patients with motor disorders of the duodenal papilla $(39,40)$, and it is one of the active ingredients in coumarin that has been habitually consumed for a long time, particularly in Europe (41). Suitability for oral administration, low toxicity and low cost are additional advantages of MU (42).

The use of hyaluronidase for the treatment of cancer has been demonstrated in several studies $(43,44)$. However, hyaluronidase is produced from bovine testis, and its clinical use has been discontinued due to allergic reactions, since the enhancement of hyaluronidase activity in healthy tissues has been observed to cause inflammation or pain in joints $(43,44)$. Targeting cluster of differentiation (CD) 44 has been suggested as an alternative candidate to targeting HA (45). CD44 has attracted attention as a stem cell marker of pancreatic cancer, along with CD24 and epithelial-specific antigen (46). CD44 is able to bind to $\mathrm{HA}$ in the ECM and enhance cancer cell proliferation, invasion and metastasis (45). Pancreatic cancer cells expressing CD44 demonstrated the characteristic features of cancer stem cells, including upregulation of signaling pathways, self-renewal and enhanced tumorigenesis (46). These properties enable cancer cells to develop tolerance against chemotherapeutic agents and radiation (46). In a previous study, an anti-CD44 antibody demonstrated anticancer efficacy by controlling HA bioactivity. However, this antibody is expensive, and similar to other molecular targeting agents, it may not be used in a clinical setting for a long time.

In conclusion, in the present study, MU demonstrated an antitumor effect without exerting any toxic effects in cells. MU was able to inhibit HA synthesis in cancer cells, thus making the ECM more appropriate for drug delivery. Further studies are required on the side effects of MU in vivo and the synergistic effect of combining MU with other anticancer agents. The use of MU may contribute to more effective pancreatic cancer treatments due to its chemosensitizer properties.

\section{Acknowledgements}

The authors would like to thank Professor Hiroshi Kijima and Dr Satoko Morohashi (Department of Pathology and Bioscience, Hirosaki University, Graduate School of Medicine, Hirosaki, Japan) for their excellent technical help, as well as Professor Makoto Hayakari (Department of Pharmacy, Hirosaki University Hospital, Hirosaki, Japan) for kindly providing the cells used in the present study.

\section{References}

1. Weissmann B and Meyer K: The structure of hyalobiuronic acid and of hyaluronic acid from umbilical cord. J Am Chem Soc 76: $1753-1757,1954$

2. Weigel PH, Hascall VC and Tammi M: Hyaluronan synthases. J Biol Chem 272: 13997-14000, 1997.

3. Menzel EJ and Farr C: Hyaluronidase and its substrate hyaluronan: Biochemistry, biological activities and therapeutic uses. Cancer Lett 131: 3-11, 1998.

4. Auvinen P, Tammi R, Parkkinen J, Tammi M, Agren U, Johansson R, Hirvikoski P, Eskelinen M and Kosma VM: Hyaluronan in peritumoral stroma and malignant cells associates with breast cancer spreading and predicts survival. Am J Pathol 156: 529-536, 2000.

5. Zhang L, Underhill CB and Chen L: Hyaluronan on the surface of tumor cells is correlated with metastatic behavior. Cancer Res 55: 428-433, 1995.

6. Simpson MA, Reiland J, Burger SR, Furcht LT, Spicer AP, Oegema TR Jr and McCarthy JB: Hyaluronan synthase elevation in metastatic prostate carcinoma cells correlates with hyaluronan surface retention, a prerequisite for rapid adhesion to bone marrow endothelial cells. J Biol Chem 276: 17949-17957, 2001. 
7. Itano N, Atsumi F, Sawai T, Yamada Y, Miyaishi O, Senga T, Hamaguchi M and Kimata K: Abnormal accumulation of hyaluronan matrix diminishes contact inhibition of cell growth and promotes cell migration. Proc Natl Acad Sci USA 99: 3609-3614, 2002.

8. Anttila MA, Tammi RH, Tammi MI, Syrjänen KJ, Saarikoski SV and Kosma VM: High levels of stromal hyaluronan predict poor disease outcome in epithelial ovarian cancer. Cancer Res 60 : $150-155,2000$.

9. Lokeshwar VB, Rubinowicz D, Schroeder GL, Forgacs E, Minna JD, Block NL, Nadji M and Lokeshwar BL: Stromal and epithelial expression of tumor markers hyaluronic acid and HYAL1 hyaluronidase in prostate cancer. J Biol Chem 276 11922-11932, 2001.

10. Setälä LP, Tammi MI, Tammi RH, Eskelinen MJ, Lipponen PK, Agren UM, Parkkinen J, Alhava EM and Kosma VM: Hyaluronan expression in gastric cancer cells is associated with local and nodal spread and reduced survival rate. Br J Cancer 79 : $1133-1138,1999$.

11. Ropponen K, Tammi M, Parkkinen J, Eskelinen M, Tammi R, Lipponen P, Agren U, Alhava E and Kosma VM: Tumor cell-associated hyaluronan as an unfavorable prognostic factor in colorectal cancer. Cancer Res 58: 342-347, 1998.

12. Collier AC, Tingle MD, Keelan JA, Paxton JW and Mitchell MD: A highly sensitive fluorescent microplate method for the determination of UDP-glucuronosyl transferase activity in tissues and placental cell lines. Drug Metab Dispos 28: 1184-1186, 2000.

13. Nakamura T, Takagaki K, Shibata S, Tanaka K, Higuchi T and Endo M: Hyaluronic-acid-deficient extracellular matrix induced by addition of 4-methylumbelliferone to the medium of cultured human skin fibroblasts. Biochem Biophys Res Commun 208: $470-475,1995$

14. Kakizaki I, Kojima K, Takagaki K, Endo M, Kannagi R, Ito M, Maruo Y, Sato H, Yasuda T, Mita S, et al: A nove mechanism for the inhibition of hyaluronan biosynthesis by 4-methylumbelliferone. J Biol Chem 279: 33281-33289, 2004.

15. Kudo D, Kon A, Yoshihara S, Kakizaki I, Sasaki M, Endo M and Takagaki K: Effect of a hyaluronan synthase suppressor, 4-methylumbelliferone, on B16F-10 melanoma cell adhesion and locomotion. Biochem Biophys Res Commun 321: 783-787, 2004

16. Yoshihara S, Kon A, Kudo D, Nakazawa H, Kakizaki I, Sasaki M, Endo M and Takagaki K: A hyaluronan synthase suppressor, 4-methylumbelliferone, inhibits liver metastasis of melanoma cells. FEBS Lett 579: 2722-2726, 2005.

17. Piccioni F, Malvicini M, Garcia MG, Rodriguez A, Atorrasagasti C, Kippes N, Piedra Buena IT, Rizzo MM, Bayo J, Aquino J, et al: Antitumor effects of hyaluronic acid inhibitor 4-methylumbelliferone in an orthotopic hepatocellular carcinoma model in mice. Glycobiology 22: 400-410, 2012.

18. Lokeshwar VB, Lopez LE, Munoz D, Chi A, Shirodkar SP Lokeshwar SD, Escudero DO, Dhir $\mathrm{N}$ and Altman $\mathrm{N}$ : Antitumor activity of hyaluronic acid synthesis inhibitor 4-methylumbelliferone in prostate cancer cells. Cancer Res 70 2613-2623, 2010

19. Pályi-Krekk Z, Barok M, Isola J, Tammi M, Szöllosi J and Nagy P. Hyaluronan-induced masking of ErbB2 and CD44-enhanced trastuzumab internalisation in trastuzumab resistant breast cancer. Eur J Cancer 43: 2423-2433, 2007.

20. Vincent A, Herman J, Schulick R, Hruban RH and Goggins M: Pancreatic cancer. Lancet 378: 607-620, 2011.

21. Raimondi S, Maisonneuve P and Lowenfels AB: Epidemiology of pancreatic cancer: An overview. Nat Rev Gastroenterol Hepatol 6: 699-708, 2009.

22. Berrino F, De Angelis R, Sant M, Rosso S, Bielska-Lasota M, Coebergh JW and Santaquilani M; EUROCARE Working group: Survival for eight major cancers and all cancers combined for European adults diagnosed in 1995-99: Results of the EUROCARE-4 study. Lancet Oncol 8: 868, 2007.

23. Cheng XB, Sato N, Kohi S and Yamaguchi K: Prognostic impact of hyaluronan and its regulators in pancreatic ductal adenocarcinoma. PLoS One 8: e80765, 2013.

24. Nakazawa H, Yoshihara S, Kudo D, Morohashi H, Kakizaki I, Kon A, Takagaki K and Sasaki M: 4-methylumbelliferone, a hyaluronan synthase suppressor, enhances the anticancer activity of gemcitabine in human pancreatic cancer cells. Cancer Chemother Pharmacol 57: 165-170, 2006.
25. Knudson CB and Toole BP: Changes in the pericellular matrix during differentiation of limb bud mesoderm. Dev Biol 112: 308-318, 1985.

26. Lin W, Shuster S, Maibach HI and Stern R: Patterns of hyaluronan staining are modified by fixation techniques. J Histochem Cytochem 45: 1157-1163, 1997.

27. Chichibu K, Matsuura T, Shichijo S and Yokoyama MM: Assay of serum hyaluronic acid in clinical application. Clin Chim Acta 181: 317-323, 1989.

28. Barbosa H, Slater NK and Marcos JC: Protein quantification in the presence of poly(ethylene glycol) and dextran using the Bradford method. Anal Biochem 395: 108-110, 2009.

29. Nojiri S and Joh T: Albumin suppresses human hepatocellular carcinoma proliferation and the cell cycle. Int J Mol Sci 15: 5163-5174, 2014

30. Decker T and Lohmann-Matthes ML: A quick and simple method for the quantitation of lactate dehydrogenase release in measurements of cellular cytotoxicity and tumor necrosis factor (TNF) activity. J Immunol Methods 115: 61-69, 1988.

31. Andarini S, Kikuchi T, Nukiwa M, Pradono P, Suzuki T, Ohkouchi S, Inoue A, Maemondo M, Ishii N, Saijo Y, et al: Adenovirus vector-mediated in vivo gene transfer of OX40 ligand to tumor cells enhances antitumor immunity of tumor-bearing hosts. Cancer Res 64: 3281-3287, 2004.

32. Stern M and Stern R: An ELISA-like assay for hyaluronidase and hyaluronidase inhibitors. Matrix 12: 397-403, 1992.

33. Luna LG (ed): Manual of Histologic Staining Methods of the Armed Forces Institute of Pathology. 3rd edition. Blakiston Division, McGraw-Hill, New York, 1968.

34. Meyer LJ and Stern R: Age-dependent changes of hyaluronan in human skin. J Invest Dermatol 102: 385-389, 1994.

35. Knudson W, Biswas C and Toole BP: Interactions between human tumor cells and fibroblasts stimulate hyaluronate synthesis. Proc Natl Acad Sci USA 81: 6767-6771, 1984.

36. Sironen RK, Tammi M, Tammi R, Auvinen PK, Anttila M and Kosma VM: Hyaluronan in human malignancies. Exp Cell Res 317: 383-391, 2011.

37. Buckway B, Wang Y, Ray A and Ghandehari H: Overcoming the stromal barrier for targeted delivery of HPMA copolymers to pancreatic tumors. Int J Pharm 456: 202-211, 2013.

38. Camenisch TD, Spicer AP, Brehm-Gibson T, Biesterfeldt J, Augustine ML, Calabro A Jr, Kubalak S, Klewer SE and McDonald JA: Disruption of hyaluronan synthase-2 abrogates normal cardiac morphogenesis and hyaluronan-mediated transformation of epithelium to mesenchyme. J Clin Invest 106 : 349-360, 2000.

39. Garrett ER, Venitz J, Eberst K and Cerda JJ: Pharmacokinetics and bioavailabilities of hymecromone in human volunteers. Biopharm Drug Dispos 14: 13-39, 1993.

40. Fontaine L, Grand M, Molho D, Chabert MJ and Boschetti E: Choleretic, spasmolytic and general pharmacologic activities of 4-methylumbelliferone. Therapie 23: 51-62, 1968 (In French).

41. Hoult JR and Payá M: Pharmacological and biochemical actions of simple coumarins: Natural products with therapeutic potential. Gen Pharmacol 27: 713-722, 1996.

42. Karbownik MS and Nowak JZ: Hyaluronan: Towards novel anti-cancer therapeutics. Pharmacol Rep 65: 1056-1074, 2013

43. Baumgartner G, Gomar-Höss C, Sakr L, Ulsperger E and Wogritsch C: The impact of extracellular matrix on the chemoresistance of solid tumors - experimental and clinical results of hyaluronidase as additive to cytostatic chemotherapy. Cancer Lett 131: 85-99, 1998.

44. Whatcott CJ, Han H, Posner RG, Hostetter G and Von Hoff DD: Targeting the tumor microenvironment in cancer: Why hyaluronidase deserves a second look. Cancer Discov 1: 291-296, 2011.

45. Takada M, Yamamoto M and Saitoh Y: The significance of CD44 in human pancreatic cancer: II. The role of CD44 in human pancreatic adenocarcinoma invasion. Pancreas 9: 753-757, 1994.

46. Tang SC and Chen YC: Novel therapeutic targets for pancreatic cancer. World J Gastroenterol 20: 10825-10844, 2014. 